\title{
Strategic tools in China/strategic tools: An investigation into strategy in practice in China
}

\author{
Hui He*, Nelson António and Álvaro Rosa \\ Management Department, ISCTE-IUL Instituto Superior de Ciências do Trabalho e da Empresa - Instituto Universitario \\ de Lisboa, Portugal. \\ Accepted 21 February, 2012
}

\begin{abstract}
In the last decades, we have been observing an increasingly dynamic and turbulent environment, where change seems to be something unavoidable and ubiquitous. This scenario of permanent instability has boosted strategy significance since its object of study is the relationship between organizations and their environment. Besides, the increased complexity agonizes the limitations of human cognition and increases bias in strategic decisions. Under this prism, companies throughout the world search for strategic practices that enable them to handle the environment volatile conditions. Therefore, strategic tools such as SWOT Analysis, Scenario Analysis or Balanced Scorecard have progressively gained importance in organizational life. Some literature also indicates that strategy tools are important to create a sense of organizational direction and to improve strategic thinking. Moreover, companies invest vast amount of resources (for example, time, money, intellectual capital) in acquiring and implementing the tools. There have not been that many studies concerning strategic tools use around the world. For a more meaningful observation of strategic tools use in a wider geographical area we have conducted a strategic tools use survey in Mainland China. The study was spread out to Beijing city, Shaanxi province and Shanxi province and 158 questionnaires were collected. From our survey, we found that SWOT analysis is the most used tool, and followed by PEST Analysis, Brain Storming and Resource Analysis. In addition, our findings in regard to large size companies show that they consider strategic tool increase the rational of the decision making and helped to clarify the strategy of the company.
\end{abstract}

Key words: Strategic tools, strategy-as-practice, China.

\section{INTRODUCTION}

Contemporary strategy tools and techniques such as SWOT analysis or Scenario analysis all promise to make managers more successful in a digital age. However, what is the present situation of strategy tools usage? One way to answer this question is to look at how they run their businesses and, in particular, at the strategy tools they use to help them. Jarzabkowski and Kaplan pointed out that although, strategy tools are being taught in many business schools there is an absence of in depth information regarding how these tools are actually used (Jarzabkowski and Kaplan, 2006). The emergence of strategy as practice challenged researchers to focus on

*Corresponding author. E-mail: amberhehui@hotmail.com. Tel. $00351-925012832$. the real things of strategy, that is, the practices, the practitioners and the praxis of strategy (Whittington, 2006; Jarzabkowski et al., 2007).

"Organizations are complex phenomena and managing them is a difficult, nuanced business, requiring all sorts of tacit understanding that can only be gained in context" (Mintzberg et al., 2005). Recent research on strategy (Chia, 2004; Whittington, 2006; Jarzabkowski, 2008) has taken a practical stance as compared to the theoretical stance of the past. This stance reflects the critical choices about who to involve in strategy, what to do in strategizing activity, and which strategizing methodologies to use in order to guide this activity. Despite this newly developing studies, Volberda (2004) noted that "the strategy field is replete with competing prescriptions and directives with regard to successful performance. "So far, current research has only 
focused on the intended 'textbook' purposes of strategy tools. We argue that we need to know much more about how these tools are used and for what purposes.

Considering the growing importance of strategic tools in today's unpredictable environment several authors pointed out that there is little research about them (Clark, 1997; Gunn and Williams, 2007; Knott, 2005; Stenfors et al., 2007; Whittington, 2002, 2003).

More specifically, we claim that there is a lack of knowledge about strategy tools used in companies. In this line of reasoning, our argument here is to study the strategy tools used by the large companies in China. Five research questions: what is the frequency of each Strategy Tools usage; why do the managers use these strategy tools; how are these strategy tools being disseminated and what is the general way of applying Strategy Tools; and finally what are the bottlenecks when managers' using strategy tools? These questions are practically important. They are also in tune with the 'practice turn' in contemporary organization and social theory (Schatzki et al., 2000; Brown and Duguid, 2001; Orlikowski, 2002).

A questionnaire research design was chosen to collect descriptive data. The target populations were the practitioner members of the China consultant companies, univeristies, government and large size companies. Descriptive statistics were obtained for the sample using the SPSSx statistical analysis package. Frequency results were collated in tabular and graphical form to identify patterns and trends.

\section{LITERATURE REVIEW}

The emergence of strategy as practice perspective highlighted the need to focus on the practical things of strategy, that is, the practitioners, the practices and the praxis (Jarzabkowski et al., 2007; Whittington, 2006). In this sense, strategy tools are important practices that deserve our attention at the empirical level since they have a relevant role in companies' strategy work.

Clark and Scott (1999) considered a strategy tool "....as a generic name for any methods, models, techniques, tools, frameworks, methodologies and approaches which provide decision support". Stenfors (2007a) revealed that a strategy tool can be conceptual (like those used in strategy design), physical (like computers and documents) or they can be process tools (such as project management techniques).

Bechky (2003) said a tool is an artefact around which activity and organizing takes place. Therefore, a tool is a means to an end (Eilon, 1980), a mediator of activity that establishes the connection between practitioners and praxis (Jarzabkowski, 2003).

In this research project, strategy tools are conceived as any artefact (conceptual, process oriented or physical) that is used by managers to engage in some kind of strategic work which is the praxis of strategy (for example, planning, analysing, presenting, debating). As it is possible to find hundreds of strategy tools in the literature (Stenfors, 2007b) we will focus mainly on those normally presented in strategy manuals.

The researches that focused on strategy tools used in companies revealed that managers prefer to use tools that are flexible, easy to learn and use, and that are well tested and established (Frost, 2003; Rigby and Bilodeau, 2005; Stenfors et al., 2007). In this respect, Jarzabkowski and Wilson (2006) claim that practitioners frequently use the tools they have at hands, the ones that hold more technical, cultural and linguistic legitimacy and that are easier to adapt to goals. Hence, this may be the reason why managers stick to the classic tool's like SWOT Analysis. This strategy tool has been consistently reported as the most used tool in companies (Clark, 1997; Frost, 2003; Gunn and Williams, 2007; Stenfors et al., 2007).

The disseminators of strategy tools are also important players to inform how these instruments are used in companies. In this regard, it is generally accepted that the main disseminators are business schools, consulting firms, text books, and popular management literature such as magazines and newspapers (Clark, 1997; Jarzabkowski, 2004; Jarzabkowski and Wilson, 2006; Stenfors and Tanner, 2006, 2007). However, there are no reports on the influence of these players in company's' choices.

According to Gunn and Williams (2007) the researches that have been conducted on strategy tools focused more on what strategy tools are used than on why or how they are applied. Hence, the reasons of strategy tools use are still a little known topic. Nonetheless, some accounts suggest that managers tend to use strategy tools mostly because of efficiency and legitimacy than creativity (Jarzabkowski and Wilson, 2006; Stenfors et al., 2007).

The majority of strategy tools reports assume that they are used as prescribed (Gunn and Williams, 2007; Stenfors, 2007b). Nevertheless, some authors fiercely dispute this view considering that tools are generally adapted by managers in practice. Put differently, managers seldom use tools in the ways intended by the tool developers because they have the need to adapt and use the parts of the tools that best serves the requirements of the situation they face (Kaplan and Jarzabkowski, 2006; Stenfors and Tanner, 2007). Thus, it is suggested that managers engage in bricolage activity (Baker et al., 2003) to adjust the tools to the context of their use (Kaplan and Jarzabkowski, 2006).

To conclude, we hold the idea that few researches have been directed to study the strategy tools used by companies. In this sense, we aim to increase our awareness on this topic by focusing on the use of strategy tool in the largest companies in China. We intend to uncover the most popular strategy tools used by firms. Additionally, we aim to address the reasons of their 
Table 1. Strategic tools usage proportions.

\begin{tabular}{lc}
\hline Strategy tools in China & Usage proportion (\%) \\
\hline Scenario analysis & 18.46 \\
Life cycle analysis & 50.85 \\
Strategic group analysis & 46.92 \\
PEST analysis & 59.91 \\
Portfolio analysis & 26.15 \\
Resource analysis & 52.31 \\
Risk analysis & 46.15 \\
SWOT analysis & 58.46 \\
Balanced scorecard & 36.92 \\
Brain storming & 56.85 \\
Value chain analysis & 36.92 \\
Generic strategies analysis & 33.85 \\
\hline
\end{tabular}

use and their deployment in practice. Thirdly, we cover strategy tools disseminators. Finally we investigated the bottlenecks of strategic tools usage. These questions are practically important. They are also in tune with the 'practice turn' in contemporary organization and social theory (Brown and Duguid, 2001; Orlikowski, 2002; Schatzki et al., 2000).

\section{RESEARCH DESIGN}

An exploratory research design has been employed to provide descriptive and explanatory data. The empirical survey was based on a written questionnaire with close-ended questions whose answer is based on 5 points Likert's scale (Appendix 1). Additionally, some open-ended questions were added for further understanding of reasons and bottlenecks in strategy tools usage. The study was replicated in northwest China (mainly from Beijing city, Shaanxi province and Shanxi province). The companies chosen were based on published records and the criteria for largest companies were based on year 2007 largest sales volume for China.

The number of complete usable returns from China was 158 collected during the period of January-May 2008 which represents a $64 \%$ of response rate and approximately $68.8 \%$ of the respondents were in top or senior executive positions greatly associated with strategy matters in the study period.

In the questionnaire, twelve strategy tools were listed according to a review of several strategy manuals (Jauch and Glueck, 1988; Montanari et al., 1990; Wheelen and Hunger, 1995, 2005; Stahl and Grigsby, 1992; Dess and Miller, 1993; Johnson and Scholes, 1993; Freire, 1999; David, 2005; Grant, 2005; Johnson et al., 2005).

All the strategy tools found in more than $70 \%$ of the reviewed manuals' were included in our list. Balanced Scorecard and Risk Analysis were added because they scored high in a study on the largest Finnish companies (Stenfors et al., 2007). Brainstorming was included since it is a different kind of tool and that was important to signal that strategy tools are broad in scope. Furthermore, respondents were encouraged to add items where they felt necessary.

Since our main goal was to provide a general picture of the comparison of strategy tools and not to test complex relationships between variables, we relied on descriptive statistics. Frequency results were drawn in tabular and graphical form to identify patterns and trends.

\section{FINDINGS AND DISCUSSION}

\section{Strategy tools used in the large companies}

The overall results are shown in Table 1. All the 12 strategy tools with the respective proportion of the samples are illustrated.

On the whole, the tools which managers most prefer are SWOT analysis, PEST analysis and Brainstorming, whereas Resource analysis, Risk analysis, Balanced Scorecard, Life Cycle analysis, Value Chain analysis and Strategic Group are moderate. Scenario Analysis, Portfolio analysis and Generic Strategies analysis are just used by few of the respondents.

In this table the foremost fact to highlight is that SWOT analysis is the most used strategy tool by companies. These findings match with other similar researches in the field that were conducted in several different geographical regions such as Australia, New Zeland, Malaysia, Hong-Kong, Singapore, United Kingdom and Finland (Clark, 1997; Frost, 2003; Gunn and Williams, 2007; Stenfors et al., 2007). Moreover, the prevalence of SWOT analysis is confirmed for Chinese firms (58.46\%).

We believe that, as a framework, SWOT analysis is highly commended for its simplicity and value in focusing attention on key issues which affect business development and growth. It has the potential to become a significant tool in identifying the factors which are most likely to influence a firm's strategy and success. On the other hand, some authors describe SWOT as item enumeration framework such as shown by Stacey (1993) or Kay (1993). This last author points out: "The best and most familiar example of an organizing framework is SWOT analysis" The continued popularity of SWOT analysis is demonstrated by its particularly basic, necessary and useful list instrument. SWOT factors 
require detailed investigation in order to understand their nature and implications for the business. There are devices available for improve SWOT charting which convert the SWOT into a true form of analysis (Pickton and Wright, 1998). In this sense, it is important that companies avoid relying exclusively in one strategy tool to produce their strategy work. As Hussey (1997) has highlighted, the use of various tools is beneficial to provide different views and perspectives.

Another extraordinary popularity strategy tools in our survey is PEST Analysis. The large enterprises showed partiality for PEST Analysis in China, which was considered the most useful strategy tool by $56.91 \%$ respondents. In analyzing the macro-environment, it is important to identify the factors that might in turn affect a number of vital variables that are likely to influence the organization's supply and demand levels and its costs (Kotter and Schlesinger, 1991; Johnson and Scholes, 1993).

The "radical and ongoing changes occurring in society create an uncertain environment and have an impact on the function of the whole organization" (Tsiakkiros, 2002). In our opinion, the use of PEST helps to break free of unconscious assumptions, and help to effectively adapt to the realities of the new environment. Especially in the case of China, several economic reforms were launched since 1979. The central government has been establishing several policies in order to decentralize economic policymaking in various sectors, especially trade.

Nowadays, enterprises are generally allowed to operate and compete on free market principles rather than under the direction and guidance of state planning as the old days. Notwithstanding, Chinese society is passing through a stage of transference which demands Chinese firms to consider and analyze the macroenvironment, the reason is why Chinese firms pay so much attention to PEST Analysis.

In our study, Brainstorming is another popular choice of managers in strategic management. We may conclude that these popular used strategy tools are simple or used in intuitive ways. This is an additional point to the widely spread notion that managers do prefer simpler tools and easy approaches.

Resource/Capability/Competences Analysis is another tool also used by a considerable number of companies (52.31\% of China). This result proposes that firms reveal a great concern on understanding and identifying the value of their resources, capabilities and competences. Therefore, this may suggest that resource-based view ideas (Barney, 1991), a school of strategy that gained momentum during the 1990s, are now widely spread throughout Chinese managers' minds. Contrasting to our results are the ones in companies from a UK economic region (Gunn and Williams, 2007), where 15\% of the companies use resource analysis and $32 \%$ core competence analysis.

In contrast, Scenario Planning just obtained only $18.46 \%$ in China. It is worth to note, some authors claimed Scenario Planning has gained increased attention recently (Burt and van der Heijden, 2002; Chermack, 2005). Such an approach to strategy may have important implications for decision making. However a lack of research leaves this relationship in the abstract domain. Chermack's theoretical model (2005) of Scenario Planning is the only publication to explicitly include decision making as a critical component of the Scenario Planning intervention and is complete with theoretical propositions and hypotheses. The difficulties encountered by Chermack were in measurement. Chermack did not specify a particular empirical indicator for measuring decision-making performance. Thus, there is a lack of the theoretical direction for practitioners.

There are also other findings in our study that are quite relevant. First of all, Balanced Scorecard is a relatively moderate strategic management tool (Antonio, 2006). It is being used by $36.92 \%$ of Chinese companies. Another issue that comes to light is the diminishing interest on the methodologies created by Porter (1985). For instance, Value Chain obtained only $36.92 \%$ of Chinese respondents' preferences. If we look at the results of comparative studies, the disappointment is even bigger. In an economic region of the UK only $20 \%$ of the firms adopt the Value Chain analysis (Gunn and Williams, 2007) and in the largest Finnish companies the result drops to $6 \%$.

The other Porter's strategic tool, the Generic Strategies framework is even used by fewer companies: only $33.85 \%$ in China have included it in their portfolio of tools used. On the other hand, Portfolio Analysis (the BCG matrix and McKinsey matrix) are used by $26.15 \%$ in China firms. Hence, tools from the positioning school of strategy are becoming less considered by practitioners. One additional thought on the findings is that most Chinese managers focused on domestic challenges and view continued rapid economic growth as essential to maintaining social stability. In practice, Chinese foreign policy reflects efforts to balance strategic and economic considerations and to coordinate the activities of diverse Chinese economic and political actors to advance national goals. This philosophy explains why Chinese companies prefer to combine SWOT with PEST and Brainstorming Analysis to evaluate the economic situation. For another, the prevalence rate of using strategy tools in China is quite low. Therefore managers should step up promoting these helpful tools.

\section{Disseminatiors of strategic tools}

The second question we have addressed in our survey is where the practitioners get to know the tools they use. As the Table 2 shows, the majority of the respondents mentioned "Education and Training programs" as their main source of information. This fact may suggest that business schools and academic institutions have the 
Table 2. Forms of accessing strategic tools.

\begin{tabular}{lc}
\hline Forms of accessing tools & Proportions (\%) \\
\hline Consulting firm/ external consultant & 64.62 \\
Specialized literature & 38.46 \\
Education and training & 64.62 \\
Internet searches & 33.85 \\
Magazines and newspapers & 18.46 \\
\hline
\end{tabular}

most prominent role in the diffusion of strategy tools. Strategy creation and development is a cerebral process that forms the basics of strategic thinking. The importance of strategic thinking need has long been identified in specialized literature (Mintzberg et al., 1998). Effectively, the results indicate that business courses and programs do teach managers ways of basic strategic thinking.

In China, consulting firms are the top source for accessing the strategy tools. This is a hint of lack of communication between academics and practitioners as suggested by Maclean and Macintosh (2002), Tranfield and Starkey (1998) and Whittington (2004). Bad communication is causing a problem between the creators and users of strategy tools. Furthermore, the excessive abstraction of academics in some situations and the over focus of managers in practicalities may also aggravate this problem. Managers' temptation for simpler approaches and intuitive uses lead them to disregard new forms of knowledge.

'Magazines and Newspapers' qualify as the lowest rank. When managers do need to get themselves informed they search for specialized literature rather than popular literature. There can be some possible explanations for this phenomenon. First of all, managers may have consciously not selected this alternative even if they rely on popular literature. This could happen if they consider inadequate for professional managers' to rely on less professional sources. Secondly, it may be that the popular literature is less powerful, attractive and convincing than literature from other countries (for example, United States) which is normally very appealing.

\section{Reasons of strategic tools use}

It is universally appreciated that strategists have cognitive limitations. Simon's (1955) concept of bounded rationality, where managers try to rationalize the irrational, that is the environments in which they operate, highlights the limitations of human cognition and the bias, or subjectivity, in the process of strategic decisionmaking. This perspective on management cognition has important implications for the understanding of tools usage in strategy.
Many authors have argued that strategic tools can assist in providing a structure for analysis, communication, assisting with coordination and in complex and adaptive situations, providing insights into strategy by presenting information in a particular way (Clark, 1997; Hussey, 1997). Some authors suggest that the search for more objectivity, rationality and efficiency in strategy decision making process is the main reason for managers to use strategy tools (Kaplan and Jarzabkowski, 2006; Stenfors et al., 2007). In our questionnaire, we listed a set of alternatives and asked respondents to classify them according to their importance. The results are shown in Table 3.

The outcome of this research seems to confirm that one problem keeping executives awake at night is the gnawing feeling that they do not know enough about the objectivity of their decision. The majority of the companies $(93.85 \%$ in China) of survey respondents agree with the statement "Make decisions more rational, objective and transparent". Respondents also feel they are not doing a good enough job of "Clarify Company's strategy".

The respondents had also voted heavily on "Encourage new ideas and creative visions" and "Understand reality and key strategic factors". Stenfors and Tanner (2007) suggested that managers tend to use strategy tools more to boost efficiency than creativity. However, creativity ranks third in China. De Wit and Meyer (2004) recognize a strategic tension between logic and creativity, deliberateness and emergence. It seems that more strategy tools shall be invented in order to generate creativity and innovation. It can also mean that managers have to be convinced that they can and should use strategy tools to enact creative activities.

In China, most strategy tools come from western countries, therefore, the paradigm originally worked out on that environment may vary widely in the Chinese situation. If Chinese companies wanted to achieve to deploy these tools domestically they should emphasize the ability of creativity, otherwise, it will not be successful. This conclusion also can be proved by another result of our survey.

In our empirical research we asked the managers to prioritize the three general ways of applying strategy tools. The findings are summarized in Table 4.

We realized, with surprise, that the second preferred 
Table 3. Reasons for strategy tools used by the large chinese companies.

\begin{tabular}{lccc}
\hline Reasons for tools use & $\begin{array}{c}\text { Important or } \\
\text { highly important } \\
(\%)\end{array}$ & $\begin{array}{c}\text { Moderately } \\
\text { important (\%) }\end{array}$ & $\begin{array}{c}\text { Little Importance or } \\
\text { not important (\%) }\end{array}$ \\
\hline Make decision more rational, objective and transparent & 93.85 & 6.15 & 0.00 \\
Clarify company's strategy & 93.85 & 4.62 & 1.54 \\
Encourage new ideas and creative visions & 83.08 & 13.85 & 3.08 \\
Understand reality and key strategic factors & 81.54 & 12.31 & 6.15 \\
Facilitate the collection and analysis of information & 80.00 & 15.38 & 4.62 \\
Strengthen team spirit and people commitment with organization & 78.46 & 13.85 & 7.69 \\
Facilitate communication and Generate Dialogue & 78.46 & 13.85 & 7.69 \\
Support the implementation of strategy at all levels & 76.92 & 12.31 & 10.77 \\
Facilitate the planning process & 72.31 & 20.00 & 7.69 \\
Facilitate the coordination and alignment of different interests & 64.62 & 26.15 & 9.23 \\
Clarify and justify difficult decisions & 60.00 & 30.77 & 9.23 \\
\hline
\end{tabular}

Table 4. Priorities in the general ways of applying strategy.

\begin{tabular}{lccc}
\hline Priority of strategic tools & A & B & C \\
\hline Percent of times as 1st priority & 12.31 & 66.15 & 21.54 \\
Percent of times as 2nd priority & 26.15 & 24.62 & 49.23 \\
Percent of times as 3rd priority & 61.54 & 9.23 & 29.23 \\
\hline
\end{tabular}

way for managers to act upon tools was to use their ideas to create their own tools. From these numbers we may highlight that companies displayed a creative behavior (about $71 \%$ proportion as a first or second priority), that is, they create their own tools to deal with their needs and challenges.

We also found that managers typically act upon tools by adapting them to the situation they have at hands ( $91 \%$ as a first or second priority). Besides, we noticed that managers seldom use the tools as they were prescribed.

\section{The Bottleneck in using strategy tools}

What is the right bag of tools for top executives today? "It is a mistake to put too much emphasis on the tools themselves. We feel that you can no more judge the quality of a manager by his choice of tools than you can a skier by his or her choice of skis and boots" (Rigby and Gillies, 2000). In a fashion of open-ended question, Chinese senior executives were asked to describe the practical problems them confront concerning gap between theory and practice and problems within strategy implementation, the main concerns are listed as follows:

(1) Gap between theory and practice:

i. Decision-making is impacted by strong policy guidance in China.

ii. There are plenty of issues in practice that does not exist in theory.

iii. The external environment is too unpredictable and complicated.

iv. It is very hard to obtain the exact and actual data of internal and external environment.

$v$. The key points of strategic influence factors always are unclear.

vi. The criteria and measurement to further processing or refining data are comparatively difficult.

(2) The practical problems are:

i. The abilities of employees are uneven.

ii. Company behavior is not synchronized with strategies.

iii. The methods are not able to complement with other strategies.

From the references in the forregoing, the main problem seems lying on competences in human resources, and it seems that it could easily be solved as a medium term objective through education training.

\section{Conclusions}

This exploratory research has provided new descriptive analysis of strategy tools use and which are the top tools used by practitioners in China. In addition, some 
evidences are presented in this paper in regard to the reasons for their application.

The results concerning the top tool are quite interesting as they do not only delineate the conditions of current tool use practices but also reveal insights with significant managerial and academic implications. The top tools were striking and unexpected, which include the dominant tool of SWOT analysis, PEST, Brainstorming and Resource analysis; whereas, Scenario analysis, Generic Strategies analysis was just used by a few of the respondents.

Regarding the choice of strategy tools, we conclude that business schools and academic institutions are the prominent disseminators of these instruments. We also found out that practitioners do not usually get informed of strategy tools through literature readings, but when they do, they clearly prefer specialized literature over the so called popular management series. Thus, the results suggest that managers seek direct orientation (for example, programs, seminars, consultants) to access the knowledge about strategy tools and they rely little on selfreadings.

Although, Chinese managers' primary reason for strategy tools use is related with efficiency, rationality and legitimacy, there is a great different view if the tools could be considered as instruments to enhance creativity or innovation. Our research strongly confirmed that managers do prefer using tools to enhance creativity in China.

A final note, the depth in terms of tools usage in China is not satisfactory. The business schools, academics and researchers, professional associations and practitioners still have an important task to bring out to the business community new tools, namely the systems base, such as Balanced Scorecard or TQM, so enhanced decisions and decision-making could be preceded.

\section{LIMITATION AND FUTURE STUDY}

This exploratory research project has provided new descriptive evidence of the levels of tool support and the top tools which are used in China for a series of core strategic tasks. It is the first empirical study to have linked the use of tools with specific strategic tasks and therefore provides more detailed information than has been available previously. But as signalled this paper contains only partial results from a major exploratory study of tool usage and tool selection in China.

A series of potential topics which follows on from this research would include: further international comparative studies of tool usage to contrast with these China results, industry-specific studies of tool usage practices, which include the link with performance, and qualitative research for in-depth examination of the application process in-volved with key tools. Historical and/or longitudinal studies of the 'life cycle' of specific tools would be useful, as well as the development of new technological and integrative frameworks. This is a new and important area of focus for strategic tools which promises to significantly enhance our knowledge of the impact of strategic tools on competitive strategy making; this will ultimately assist practitioners to improve the future prospects and performance of their organizations.

\section{REFERENCES}

Adam F, Brezillon P, Carlson S, Humphreys P (2005). Creativity and innovation in Decision making and Decision support, London, UK: Decision support Press, pp. 693-710

Antonio dos Santos N (2006). Balanced score carde Mapas Estategicos, Grupo Estrategia Organizacional/ISCTE- Working paper No. $1 / 06$

Baker T, Miner AS, Eesley DT (2003). Improvising firms: bricolage, account giving and improvisational competencies in the founding process, Res. Policy, 32: 255-276.

Barney J (1991). Firm resources and sustained competitive advantage. J Manag., 17(1): 99-120.

Bechky BA (2003). Object lessons: workplace artifacts as representations of occupational jurisdiction, Am J Sociol., 109 (3): 720-752.

Brown JS, Duguid P (2001). Knowledge and Organization: a Socialpractice Perspective. Organiz. Sci., 12(2): 198-215.

Burt G, van der Heijden K (2002). Reframing industry boundaries for structural advantage -- the role of scenario planning, pp. 223-232.

Chermack TJ (2005). Studying scenario planning: Theory, research suggestions and hypotheses. Technological Forecasting and Social Change, 72(1): 59-73.

Chia R (2004). Strategy-in-Action: Towards a Phenomenology of Practical Coping.School of Management, Fife: University of St Andrews.

Clark DN (1997). Strategic management tool usage: a comparative study, Strategic Change, 6: 417-427.

Clark DN, Scott JL (1999). Strategic level MS/OR tool usage in the United Kingdom and New Zealand: a comparative survey, AsiaPacific J. Oper. Res., 16 (1): 35-51.

De Wit B, Meyer Ron (2004). Strategy synthesis: resolving strategy, paradoxes to create competitive advantage. Printed in Singapore by Seng Lee Press.

Dess G, Miller A (1993). Strategic Management. McGraw Hill, New York.

Eilon E (1980). The role of management science. J. Oper. Res. Soc., 31 (1): $17-28$.

Freire A (1999). Estratégia: Sucesso em Portugal. Verbo, Lisboa.Translate to English.

Frost FA (2003). The Use of Strategy Tools by Small and Medium Sized Enterprises: an Australian Study. Strategic Change, 12: 49-62.

Gunn R, Williams W (2007). Strategic tools: an empirical investigation into strategy in practice in the UK, Strategic Change, 16: 201-216.

Hussey J, Hussey R (1997) Business Research: A practical guide for undergraduate and postgraduate students. London: Macmillan Press.

Jarzabkowski P (2003). Strategic practices: an activity theory perspective on continuity and change, J Manag. Stud., 40 (1): 23-55.

Jarzabkowski $P$ (2004). Strategy as practice: recursiveness, adaptation, and practices-in-use, Organization Studies, 25 (4): 529-560.

Jarzabkowski P, Balogun J, Seidl D (2007). Strategizing: The Challenges of a Practice Perspective. Hum. Relat., 60 (1): 5-27.

Jarzabkowski P, Wilson DC (2006). Actionable strategy knowledge: a practice perspective, J Manag. Stud., 24 (5): 348-367.

Johnson G, Scholes K (1993). Exploring Corporate Strategy. Prentice Hall, London.

Kaplan S, Jarzabkowski $P$ (2006). Using Strategy Tools in Practice. How Tools Mediate Strategizing and Organizing. AIM Research Working Papers Series: 57.

Kay J (1993). The Structure of Strategy. Bus. Strategy Rev., 4 (2): 
17-37.

Knott P (2005). A typology of strategy tools applications. Manag. Decis., 44 (8): 1090-1105.

Kotter J, Schlesinger L (1991). Choosing strategies for change. Harvard Bus. Rev., pp.24-29.

Mintzberg H, Ahlstrand B, Lampel J (1998). Strategy Safari: The Complete Guide through the Wilds of Strategic Management. Financial Times, London.

Mintzberg H, Lampel J, Ahlstrand B (2005). Strategy Safari: A Guide Tour Through the Wilds of strategic Management. Free Press

Montanari JR, Morgon CP, Bracker J (1990). Strategic Management: A Choice Approach, Orlando: The Dryden Press.

Orlikowski W (2002). Knowing in Practice: Enacting a Collective Capability in Distributive Organizing. Organiz. Sci., 13(3).

Picktion W, Sheila W (1998). What is SWOT in strategic analysis, Divid strategic change, 7(2):101-109

Porter ME (1985). Competitive Advantage, Free Press, New York, 1985.

Rigby D, Bilodeau B (2005). The Bain 2005 management tool survey, Strategy \& Leadership, 33 (4): 4-12.

Rigby D, Gillies C (2000). Making the most of management tools and techniques: a survey from Bain \& Company. Strategic Change, August.

Rigby Darrell, Gillies C (2000). Making the most of management tools and techniques: a survey from Bain \& Company, Strategic Change, 9 (5): 269-274.

Schatzki T, Knorr-Cetina K, von Savigny E (2000). The Practice Turn in Contemporary Theory. London: Routledge.

Simon, Herbert A. (1955). A Behavioral Model of Rational Choice. The Q. J. Econ., 69(1): 99-118

Stacey RD (1993). Strategic Management and Organisational Dynamics. London: Pitman.

Stahl M, Grigsby D (1992). Strategic Management for Decision Making. PWS-Kent, Boston.

Stenfors S (2007a). Strategy Tools: A Set of Golf Clubs (Essay 2). In: Stenfors, S., 2007, Strategy Tools and Strategy Toys: Management Tools in Strategy Work. Unpublished Ph.D. Thesis, Helsinki School of Economics, http://hsepubl.lib.hse.fi/pdf/diss/a297.pdf Acess Date: October, 10, 2007.

Stenfors S (2007b). Strategy Tools and Strategy Toys: Management Tools in Strategy Work. Unpublished Ph.D. Thesis, Helsinki School of Economics, http://hsepubl.lib.hse.fi/pdf/diss/a297.pdf Acess Date: October, 10, 2007.

Stenfors S, Tanner L (2007). Evaluating Strategy Tools Through Activity Lens (Essay 6). In: Stenfors, S., 2007, Strategy Tools and Strategy Toys: Management Tools in Strategy Work. Unpublished Ph.D. Thesis, Helsinki School of Economics, http://hsepubl.lib.hse.fi/pdf/diss/a297.pdf Acess Date: October, 10, 2007.
Stenfors S, Tanner L (2007). High-level decision support in companies: where is the support for creativity and innovation? An essay in: Stenfors, S. 2007. Strategy tools and strategy toys: Management tools in strategy work. HSE Print.

Stenfors S, Tanner L, Syrjanen M, Seppala T, Haapalinna I (2007). Executive views concerning decision support tools. Eur. J. Oper. Res., 181(2): pp. 929-938.

Tranfield D, Starkey K (1998). The nature, social organization and promotion of management research: towards policy'. Br. J Manag., 9: 341-353.

Tsiakkiros A, Pashiardis $P$ (2002). Strategic planning and education: The case of Cyprus, 16(1): 6-17.

Volberda HW, Sidhu JS, Commandeur HR (2004). Exploring Exploration Orientation and its Determinants: Some Empirical Evidence.J. Manag. Stud., 41(6): 913-934.

Wheelen TL, Hunger DJ (1995). Strategic Management and Business Policy. Massachusetts: Addison-Wesley Publishing Company. Whittington R (2002). Practice perspectives on strategy: Unifying and developing a field, Best Paper Proceedings, Academy of Management, Denver, United States.

Wheelen TL, Hunger JD (2005). Strategy Management and Business Policy. Pearson Prentice-Hall, New York.

Whittington R (2003). The work of strategising and organising: for a practice perspective. Strategic Organisation, 1 (1): 56-65.

Whittington R (2004). Strategy after modernism: recovering practice. Eur. Manag. J. 1: 62-68.

Whittington R (2006). Completing the Practice Turn in Strategy Research. Organization Stud., 27 (5): 613-634. 


\section{APPENDIX}

Appendix 1. Questionnaire.

This Questionnaire aims to identify the instruments, models or tools used by companies in their activity with the goal of better understanding organizational strategy.

Please read carefully the instructions provided for the correct fulfillment of the answers. Please answer all the questions so that the questionnaire can be completely validated.

Company and respondent date

Company Name:

NO. of Employees(approximately):

Job Position:

Educational Background:

At the level of your company or business unit, which instruments, tools, or techniques are used or have been used in the last 5 years, in a systematic way (methodical, ordered) to support the most relevant decisions (those that imply the use of more resources and have wider scope and impact)?

Only some examples are listed. You should mark with an $X$ the instruments that are used in your enterprise and mention others that are used but are not part of the list below, we provide a brief description of each instrument.

Scenario Analysis

(Construction of different alternatives to the future taking into account different expectations)

Life Cycle Analysis. $\Gamma$ and products generally develops through stages - introduction, growth, maturity, decline - which present different patterns and characteristics that effect in strategy)

Strategic Group Analysis

(Analysis of the attractiveness of an industry through 5 forces: entry barriers to new entrants, possibility of substitutes, bargaining power of buyers and suppliers, and intensity of competition)

PEST Analysis. through political, economic, social and technological factors)

(Analysis of the environment

Portfolio Analysis (e.g. Matrix BCG, Matrix GE/McKinsey)........... variables such as growth rate and market share in order to relate the industry/market attractiveness against the competitive position of products/business units)

Analysis of Resources/Capabilities/Core Competences ............. $Г \quad$ (Identification of resources, capabilities and/or competences of the enterprise that are valuable, rare, and difficult to imitate)

Risk Analysis.

(Benefit and risk analysis of strategic options to determinate their attractiveness)

SWOT Analysis.... strengths and weaknesses, and environment opportunities and threats)

Balanced Scorecard......<smiles>[CH]1CCCC1</smiles>

(Identification of enterprise evaluate organization performance using performance measures that covers 4 perspectives - financial, clients, internal processes, learning and growth)

Brainstorming...... people are free to express their ideas and perspectives on a subject) Value Chain (M. Porter).

(Group activity where Г competitive advantage)

(Separation and analysis of enterprises diverse activities in order to identify areas of 
Generic Strategies (M. Porter)

(Model to choose one of three

generic strategies: cost, differentiation and focus)

Others (mention others instruments that are used in your enterprise)

How you company or business unit had access to the instruments identified before?

Mark with an X the option(s) that explain(s) how you have access to all the instruments identified.

Consulting firm/ External Consultant....

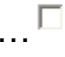

Specialized literature (books, scientific articles, etc.)...................

Education and Training (Conferences, Graduated courses, etc.)........

Internet searches..................................................

Magazines and Newspapers..........................................

Other(s)

In the implementation of the instruments identified in question 1. were used:

Mark with an X the option(s) that enable(s) to explain the implementation of all the instruments identified.

Internal Help $\quad$ External Help

Following are listed possible ways of using the instruments indicated in question 1. Order them putting the number1, 2 or 3 where 1 is the most used way and 3 the less used.

In the case you use the identifies instrument in a different way you can indicate in the space "Other(s)"

(1)The indications referred in the sources of access identified previously (e.g. magazines, consulting form, specialized literature, etc.) are followed.

(2)A partial use or adaptations of the instruments are made considering the goals of their use.

(3)The concepts and ideas of the instruments are used to create new ways of work and new tools.

(4)Other(s)

To what point the items listed following are important or not important to justify the use of the instruments that you indicated in question 1. Classify from 1 to 5 each item according to its degree of importance or unimportance.

1-Not Importance 2-little Importance 3-Moderately Important 4-Important 5-Highly Important

Mark with an X the opinion (s) that you consider more adequate. You can indicate other alternatives in the space "others"

\begin{tabular}{lccccc}
\hline & Not Imp & little Imp & Mod Imp & Imp & High Imp \\
\hline Support the implementation of strategy at all levels & 1 & 2 & 3 & 4 & 5 \\
Clarify company's strategy & 1 & 2 & 3 & 4 & 5 \\
Clarify and justify difficult decisions & 1 & 2 & 3 & 4 & 5 \\
Understand reality and key strategic factors & 1 & 2 & 3 & 4 & 5 \\
Encourage new ideas and creative visions & 1 & 2 & 3 & 4 & 5 \\
Facilitate communication and Generate Dialogue & 1 & 2 & 3 & 4 & 5 \\
Facilitate the coordination and alignment of different interests & 1 & 2 & 3 & 4 & 5 \\
Facilitate the collection and analysis of information & 1 & 2 & 3 & 4 & 5 \\
Facilitate the planning process & 1 & 2 & 3 & 4 & 5 \\
Strengthen team spirit and people commitment with organization & 1 & 2 & 3 & 4 & 5 \\
Make decision more rational, objective and transparent & 1 & 2 & 3 & 4 & 5 \\
\hline
\end{tabular}

Other(s):

6. Describe the main difficulties in the use of the instruments identified in question 1 ? 